\title{
The People, Process and Goal Model versus the Sand Cone Model of Transformational Leadership: Critical Evaluation
}

\author{
THANH HA-VIKSTRÖM \\ University of Vaasa, Finland \\ thanh.ha-vikström@student.uwasa.fi
}

\begin{abstract}
The aim of this paper is to compare and (self-)critically evaluate two leadership behaviour models that are based on the findings of the authors' previous studies. These are the Sand Cone model of transformational leadership and the People, Process and Goal model. The results expose the importance of leadership behaviour in both models. The elements incorporated in the Sand Cone model conceptualize and specify the effectiveness of transformational leadership behaviour, while different factors integrated into the People, Process and Goal model indicate the patterns of leaders' focus areas in real-life experiences. This paper contributes to the clarification of the values of these models and to the justification of prioritizing one model over the other. Both models can help leaders improve their skills and find the desired balance for their own organisational success. These empirical studies open an avenue for further research on leadership behaviour models in different types of organisations.
\end{abstract}

Key words: leadership behaviour; sand cone model; people, process and goal model; transformational leadership https://doi.org/10.26493/1854-4231.13.71-9o

\section{Introduction}

It has long been understood that leadership behaviours are major factors that influence employees' motivation and to develop their work and activities (Antonakis, Day, and Schyns 2012; Fischer, Dietz, and Antonakis 2016). Leadership behaviours are activating the company resources towards the fulfilment of the organisation's mission. Leadership behaviours are also vital for organisational innovation, adaptation, and performance (Antonakis and House 2014). Leadership behaviours matter for teams, organisations and whole nations (Day and Lord 1988; House, Spangler, and Woycke 1991; Waldman and Yammarino 1999; Flynn and Staw 2004; Jones and Olken 2005; Yukl 2008; Crossan and Apaydin 2010). 
Based on our four previous investigations, this paper aims to compare and self-critically evaluate two leadership behaviour models, the Sand Cone model of transformational leadership and the People, Process and Goal model. The Sand Cone model has been introduced and discussed in three peer-reviewed research articles (Ha-Vikström and Takala 2016a; 2016b; 2016c) where empirical data was collected via Analytic Hierarchy Process-based surveys from a global organisation (with approximately 18000 employees, located around the world). The survey was collected during two different periods in 2015 and 2016. In total 112 mid-level managers participated.

The People, Process and Goal model has been introduced in a recent peer-reviewed research article (Ha-Vikström 2017), for which the empirical data was collected via surveys and in-depth interviews of 20 managers across different organisational levels (Director, General Manager and Line Manager) from the same global organisation during 2016. This organisation was selected because the researcher has been working in this company during the last 20 years, which means the researcher intervenes in the environment (Gold 1958; McLeod 2015). This existence of a long-term relationship (between the researcher and the company) helped the researcher disclose the leaders' deeper thoughts and feelings better than otherwise would have been possible (Maclean, Harvey, and Chia 2012). In addition, as the studies focused on the leaders' behaviour and attitude, that perception could be effortlessly observed via social contact and business relationship.

The central focus of the Sand Cone model is to measure the effectiveness of leaders' performance from a transformational leadership perspective. While the central attention of the People, Process and Goal model is to measure the key focus areas of leadership in an organisation in terms of people, processes and goals. For practical implications, these models and their assessing methods can be used for recruitment, selection or promotion purposes for any organisation. These new theories provide ideas for developing training programs to support leaders and to take the organisation to the highest level of performance.

This paper not only enhances our understanding of the importance of leadership behaviours and how they can be analysed and measured, but also contributes to the clarification of the values of the two models and to the justification of prioritizing one model over the other.

The paper is structured as follows. The first the cecond section de- 
scribe the Sand Cone model and the People, Process and Goal model. The third section discusses the models' major differences and similarities. The fourth ection introduces the benefits and limitations of the models as well as how they could be combined or prioritized. Finally, the fifth section concludes with arguments about the findings and opportunities for further research.

\section{Description of the Sand Cone Model of Transformational Leadership}

Transformational leadership theory has deservedly emerged as one of the most dominant leadership theories during the last three decades (Mhatre and Riggio 2014). The baseline and purpose of transformational leadership are to inspire, to encourage and motivate each other, to trust each other and to work together towards the common goal. In other words, transformational leadership describes how a leader seeks to meet the higher-order needs of followers (Banks et al. 2016).

The extensive reviews of the Sand Cone model of transformational leadership already exists (Takala et al. 2005; Takala et al. 2006a; 2006b; Takala, Kukkola, and Pennanen 2008; Takala et al. 2008; HaVikström and Takala 2016a; 2016b; 2016c). Thus, in this section, we present briefly the description of this model.

The structure of this model is supported by four main levels; first, the highest level is the 'Directions of outputs.' The next level is 'Cornerstones' of transformational leadership followed by 'Results' level. The 'Resources' are at the ground level of the model. Each component contains different elements. Takala, Kukkola, and Pennanen (2008) and Takala et al. (2008) explain that 'each variable has been defined an optimal value, which should give the most balanced leadership. In theory, the optimal balanced leadership will be found when Directions of outputs (each 33\%), cornerstones (each 25\%) and resources (each 25\%)' (Takala et al. 2013, 78). This distribution was defined according to the idealization theory and was introduced as follows:

1. The 'Resources' level is formed by four elements: processes (PC); people, technology and expertise (Рт); information systems (Iт) and organisation groups and teams (OR). These four elements are built because when new tasks are given in new situations or new conditions; first, we would need people, technology and expertise, second, processes, then organisation and finally information system should be increased. 
2. The 'Cornerstones' level covers a group of three 'I's' element/factor and building trust element. That is, Intellectual stimulation (Is), Individualised consideration (IC), Inspirational motivation (гм) and Building trust and confidence (вт). Jung and Avolio (1999), Bono and Judge (2003), and Judge and Piccolo (2004) have proposed these four factors as follows:

- Intellectual stimulation (Is) characterizes leaders' capacity to encourage his or her followers to think out of the box, to take risks and to be innovative and creative.

- Individualized consideration (Ic) refers to leaders' ability to pay special attention to each individual follower's needs for achievement and growth.

- Inspirational motivation (IM) describes those leaders who can provide a clear vision, encourage and set high standards for followers for future goals.

- Building trust (вт) factor originates from 'Idealised Influence' by Bass and Steidlmeier (1999) to describe a role model leader for their followers. Leaders and followers relationship is based on mutual trust and demanding equality (Bass and Steidlmeier 1999; Dirks and Ferrin 2002; Judge and Piccolo 2004; Bass and Riggio 2006).

3. The 'Results' level includes three styles of leadership: passive leadership, controlling leadership (Takala et al. 2006a; 2006b) and dynamic leadership (Ha-Vikström and Takala 2016a; 2016b; 2016c) in which, passive and controlling leadership focus more on corrective actions and are least effective (Bass and Riggio 2006). In contrast, dynamic leadership is necessary because the world today becomes more complex and dynamic. Dynamic times require dynamic driven leaders (Williams 1998) who can lead with courage, passion and vision (Duffy 2006). Progen (2013) explains that dynamic leadership is a dual-focused form on both subordinates and on the situation of leadership, that allows a leader to react to changes by being proactive. Dynamic leadership accepts diversity and enables leaders to be effective leaders, and it is a source of organizational creativity and innovation. The optimal balanced leadership will be found when dynamic leadership $82 \%$, and controlling- and passive leadership is 9\% each (Ha-Vikström and Takala 2016a; 2016b; 2016c).

4. Direction of outputs incorporates three types of accomplishment: Effectiveness (EF), Satisfaction (SA) and Extra effort (EE). These accomplishments are also the main foundation of the 
'Prospector, Analyser and Defender model,' which was invented by Takala, Kukkola, and Pennanen (2008). Extra effort (EE), or Prospector (oriented for the future and extra effort), Effectiveness ( $\mathrm{EF}$ ), or Defender (oriented for current results, less effort for future), Satisfaction sA, or Analyser (oriented between prospector and defender). Examples of the transformational leadership sand cone model can be seen in Ha-Vikström and Takala (2016a; 2016b; 2016c).

TRANSFORMATIONAL LEADERSHIP INDEXES (TLI)

Five equations calculate leadership indexes (Total leadership index (TLI), Specific index; Outcomes index (OI); Leadership index (LI) and Resource index (RI)) to measure the effectiveness of leadership behaviours constructed and used in three previous research (HaVikström and Takala 2016a; 2016b; 2016c).

$\mathrm{TLI}=1-\frac{\sum \text { Absolute difference values }}{\sum \text { Optimal values }}$.

Specific index $=1-\frac{\text { Absolute difference }}{\text { Maximal difference }}$.

$\mathrm{OI}=\operatorname{Mean}($ Specific index $\{\mathrm{E} \mathrm{F}, \mathrm{SA}, \mathrm{E} \mathrm{E}\})$.

$\mathrm{LI}=\operatorname{Mean}($ Specific index $\{\mathrm{IC}, \mathrm{IM}, \mathrm{IS}, \mathrm{B} T, \mathrm{PL}, \mathrm{CL}, \mathrm{DL}\})$.

$\mathrm{RI}=$ Mean (Specific indexP $, \mathrm{PT}, \mathrm{IT}, \mathrm{OR})$.

Table 1 demonstrates an example how to calculate TLI, Specific index, Outcome index, Leadership index, Resource index and Total transformational leadership index.

$$
\begin{aligned}
\mathrm{TLI} & =1-\frac{\sum \text { Absolute difference values }}{\sum \text { Optimal values }}=1-\frac{148.43}{400}=0.63 . \\
\text { Specific index }=1-\frac{\text { Absolute difference }}{\text { Maximal difference }}=1-\frac{21.3}{66.7}=0.68 . & \\
\mathrm{OI} & =\text { Mean }(\text { Specific index }\{\mathrm{EF}, \mathrm{SA}, \mathrm{EE}\}) \\
& =\text { Mean }(\mathrm{o} .68,0.98, \mathrm{O} .66)=0.78 . \\
\mathrm{LI} & =\text { Mean }(\text { Specific index }\{\mathrm{IC}, \mathrm{IM}, \mathrm{IS}, \mathrm{BT}, \mathrm{PL}, \mathrm{CL}, \mathrm{DL}\}) \\
& =\text { Mean }(\mathrm{O} .93,0.95,0.94,0.94, \mathrm{O} .81, \mathrm{O} .98, \mathrm{O} .77)=0.90 . \\
\mathrm{RI} & =\text { Mean }(\text { Specific indexPC, } \mathrm{PT}, \mathrm{IT}, \mathrm{OR}) \\
& =\text { Mean }(11.6,23.4,9.5,2.2)=0.84 .
\end{aligned}
$$


TABLE 1 An Example of How to Calculate TL Indexes

\begin{tabular}{lrrrr}
\hline TL components and factors & $(1)$ & $(2)$ & $(3)$ & $(4)$ \\
\hline Directions of outputs & & & & \\
$\quad$ Effectiveness E F & 33.33 & 12.20 & 21.13 & 0.68 \\
Satisfaction SA & 33.33 & 32.00 & 1.33 & 0.98 \\
$\quad$ Extra Effort E E & 33.33 & 55.80 & 22.47 & 0.66 \\
\hline Cornerstones & & & & \\
Individualized consideration IC & 25.00 & 30.40 & 5.40 & 0.93 \\
Inspirational motivation IM & 25.00 & 29.00 & 4.00 & 0.95 \\
Intellectual stimulation IS & 25.00 & 20.30 & 4.70 & 0.94 \\
Building trust and confidence B T & 25.00 & 20.30 & 4.70 & 0.94 \\
\hline Results & & & & \\
Passive leadership PL & 9.00 & 26.00 & 17.00 & 0.81 \\
Controlling leadership CL & 9.00 & 11.00 & 2.00 & 0.98 \\
Dynamic leadership DL & 82.00 & 63.00 & 19.00 & 0.77 \\
\hline Resources & & & & \\
Process PC & 25.00 & 13.40 & 11.60 & 0.85 \\
People, technology, know-how P T & 25.00 & 48.40 & 23.40 & 0.69 \\
Information system IT & 25.00 & 15.50 & 9.50 & 0.87 \\
Organisation (group, teams) OR & 25.00 & 22.80 & 2.20 & 0.97 \\
\hline Total & 400.00 & & 148.43 & \\
\hline
\end{tabular}

Notes (1) optimal values, (2) response values, (3) absolute difference, (4) specific index. $\mathrm{TLI}=0.63, \mathrm{OI}=0.78, \mathrm{LI}=0.90, \mathrm{RI}=0.84$.

Table 2 (p. 77) presents the data analysis and inter-correlations between 14 factors and transformational leadership index. The correlation coefficients can vary numerically between 0.0 and 1.0. The closer the correlation is to 1.0, the stronger the relationship between the two variables. In this table, there are several correlation coefficients that indicate the existence of a medium to strong relationship, for example: (a) between effectiveness EF variable and extra effort EE variable (o.66); (b) between extra effort EE and satisfaction SA (o.52); (c) between dynamic leadership DL and passive leadership PL (0.85); (d) between controlling CL and passive leadership PL is (0.50).

\section{Description of the People, Process and Goal Model}

The People, Process and Goal model is a normative model of leadership behaviour. The model is based on ideas that relate directly to organisational practice and the real life experiences of the leaders, it is not based on any abstract hypotheses. The model describes the leaders' focus areas across different organisational levels. The ex- 
The People, Process and Goal Model

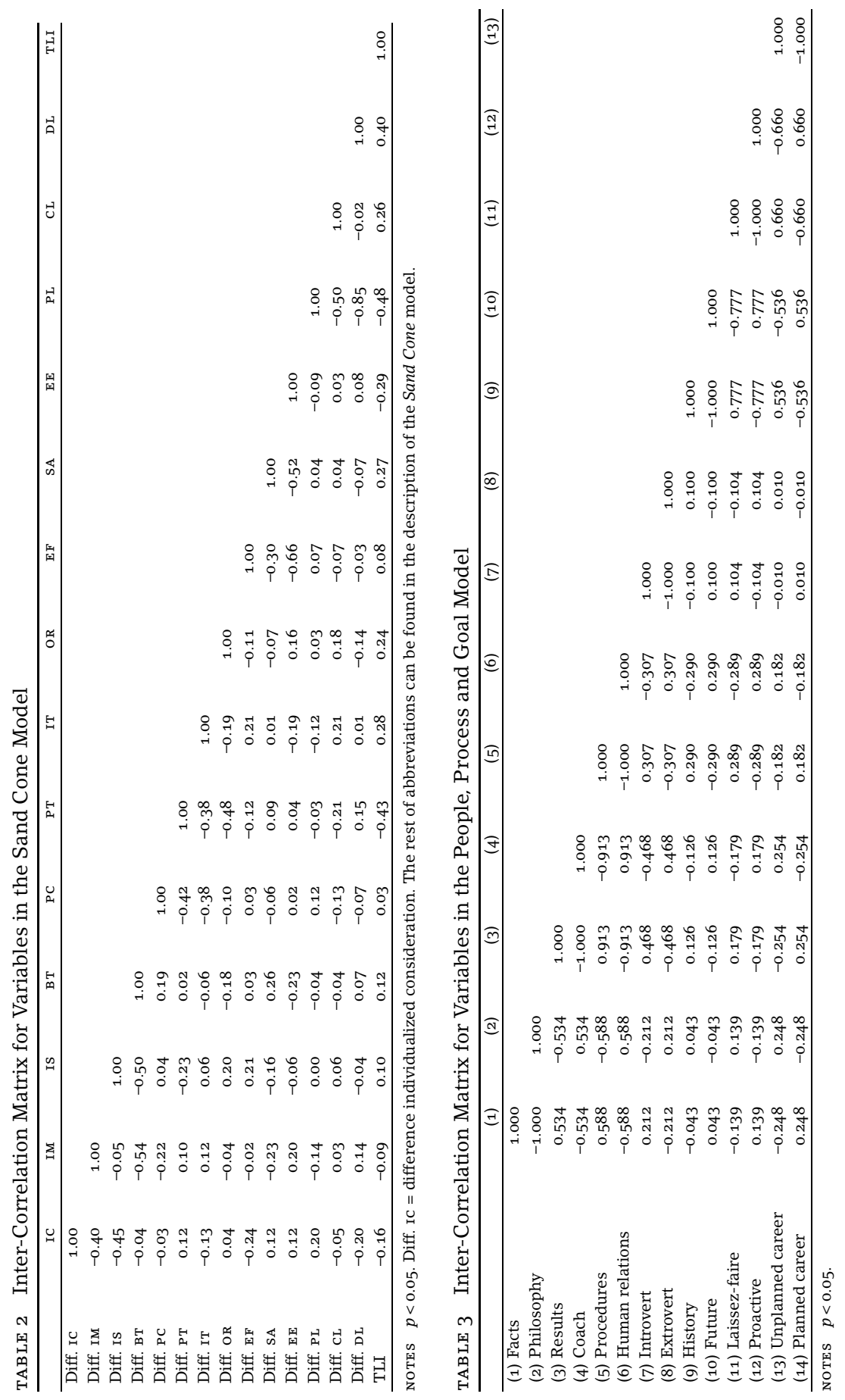




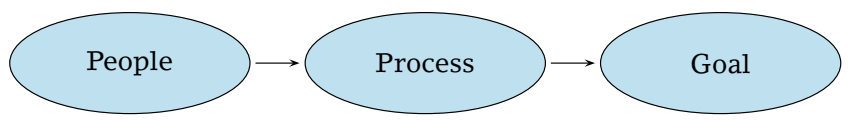

FIgURE 1 Essential Focus Areas of Leadership Behaviour: People Use Processes to Achieve a Goal

tensive reviews of the People, Process and Goal model was already explained in a recent empirical study (Ha-Vikström 2017).

Based on an investigation through a triangulation approach, the findings reveal seven specific pairwise categories reflecting leaders' behaviour and their actual deep meanings in real-life context (HaVikström 2017). Followings is a succinct explanation of these seven pairwise categories:

1. Facts versus philosophy. Facts refer here being a doer, most people work as 'doers' or contributors, their primary responsibility is to perform tasks. Philosophy refers to being a thinker, who prefers to seek a wider context, imagines different possibilities of how things should be done, considers why or how everything connects and so forth.

2. Results versus coach-oriented. In a successful organisational setting, leaders may either use behaviours and orientations, in order to lead their followers towards delivering the highest level of performance (results-oriented), or collaborate and foster an individualized relationship with their followers in order to work together on reaching an agreed-upon destination (coach-oriented).

3. Procedures versus human relations. For evaluation purposes, we use the term procedures for process and human relations for people. Process-focused leadership is a behavioural approach in which the leader focuses on the process that needs to be performed. People-focused leadership is a behavioural approach in which the leader focuses on the satisfaction, motivation and general well-being of team members.

4. Introvert versus extrovert. Introversion (reserved and solitary behaviour) and Extroversion (talkative, outgoing and energetic behaviour) are personalities' pattern of behaviour. StephensCraig, Kuofie, and Dool (2015) insist that regardless of the preference for introversion or extroversion, each individual is capable of learning and compensating for one's own weaknesses in order to adapt and operate in the corporate world, a world that may be designed for extroverts.

5. The past versus the future. 'A past-oriented leader, for example, 
may need a future-oriented person working with him to create an organizational vision and to drive strategic planning. A future-oriented leader may need a past-oriented person working with her to review past performance data and analyse trends in data to be used in future planning' (Thoms 2004, 45).

6. Laissez-faire versus proactive. In general, the laissez-faire attitude (letting things take their own course, without interfering) usually leads to lower productivity compared to a proactive attitude (take responsibility for their roles by engaging and cooperating with others, and always looking for ways to improve).

7. Unplanned career versus planned career. An essential element of leadership development is career planning. Career planning used to be considered as the responsibility of a leader. The leader either not plans his or her career for some reasons, or attempts to explore and progress his or her potential career path through different activities and set development goals.

Based on these categories, each participant's behaviour (obtained through in depth interviews, questionnaire and observations) was quantified by using a scale with five ratings: not at all (o), slightly (0.25), moderately (0.5), very (0.75) and extremely (1).

According to Brown (2003), personality is an outline of behaviour, while attitude is both a decision-oriented and learned behaviour. When we refer to a person's attitudes, we are trying to explain his or her behaviour, which in turn helps us to define how we behave towards a situation or object. With this aspect in mind, and by individually and collectively examining the data set, we found that leaders' behaviours could be categorized into different attributes. Consequently, a pattern of people-, process and goal-focused behaviours was discovered. Figure 2 demonstrates the pattern of leaders' focus areas (Ha-Vikström 2017).

Large oval on the left contains five leading attributes: Human relations* $(\mathrm{Hu})$; Philosophy* $(\mathrm{Ph})$; Proactive* (Pro); Coach* (Co); Extrovert* $^{*}(\mathrm{Ex})$. In addition, it contains two sub-attributes or non-leading attributes: Unplanned career (Un_ca) and Past $(\mathrm{Pa})$.

Large oval on the right contains one leading attribute: Procedure* (Proc) and five sub-attributes: Facts (Fa), Introvert (In), Past (Pa), Unplanned career (Un_ca), and Laissez-faire (LF).

Large oval in the middle contains three leading attributes: Results* (R), Future* (Fu), Planned career* (Pl_ca), and three sub-attributes: Introvert (In), Facts (Fa), and Laissez-faire (LF).

All leading attributes are categorized into one of the focus areas 


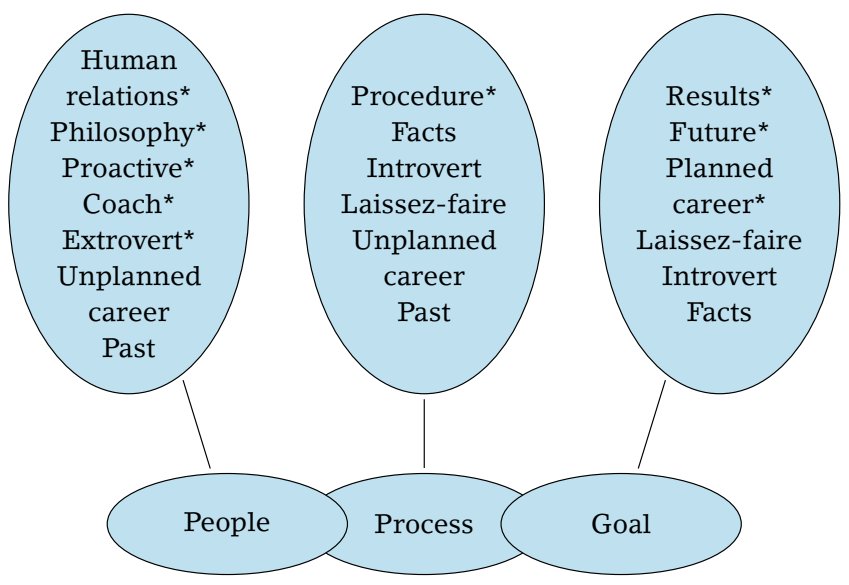

FIGURE 2 The Pattern of Leaders' Focus Areas

(e.g. human relations belongs to People, results to Goal etc.). In addition, as the sub-attributes do not naturally belong to one of the two remaining focus areas, we decided to split them evenly. With this split, the sum of all attribute pairs equals to 1 , which ensures the validity of the mathematical model. This split is visible in the mathematical formulas where the sub-attributes are always divided by 2 (Ha-Vikström 2017).

Equation 1 was used to calculate people-focused leadership behaviour index:

$$
\text { People }_{\text {focused }}=\frac{P h+C o+H u+E x+\frac{P a}{2}+P r o+\frac{U n_{\_} c a}{2}}{7} \times 100,
$$

where $P h=$ philosophy, $C o=$ coach,$H u=$ human relations, $E x=$ extrovert, $P a=$ past, $P r o=$ proactive and $U n_{-} c a=$ unplanned career.

Equation 2 was used to calculate process-focused leadership behaviour index,

$$
\text { Process }_{\text {focused }}=\frac{\frac{F a}{2}+P r o c+\frac{I n}{2}+\frac{P a}{2}+\frac{L F}{2}+\frac{U n_{-} c a}{2}}{7} \times 100,
$$

where $F a=$ facts, Proc $=$ procedures, $I n=$ introvert, $P a=$ past, $\mathrm{LF}=$ laissez-faire and $U n_{-} c a=$ unplanned career.

Equation 3 was used to calculating goal-focused leadership behaviour index,

$$
\text { Goal }_{\text {focused }}=\frac{\frac{F a}{2}+R+\frac{I n}{2}+F u+\frac{\mathrm{LF}}{2}+P l_{-} c a}{7} \times 100,
$$




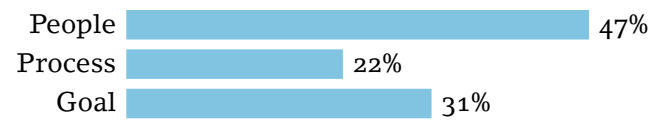

FIGURE 3 A Sample of Key Focus Areas from a Leader

where $F a=$ facts, $R=$ results, $I n=$ introvert, $F u=$ future, $L F=$ laissezfaire and $P l \_c a=$ planned career.

$$
\text { People }_{\text {focused }}+\text { Process }_{\text {focused }}+\text { Goal }_{\text {focused }}=100 .
$$

An example of how to calculate the people focus. For example, the received values from an informant based on the triangulation analysis are follows: Philosophy $=0.5$, Coach $=0.75$, Human relations $=0.75$, Extrovert $=0.75$, Past $=0.5$, Proactive $=0.5$ and Unplanned career $=1$. We apply these values on Eq.1, the People-focused index will be:

$$
\text { People }_{\text {focused }}=\frac{0.25+0.75+0.5+0.75+\frac{0.5}{2}+0.5+\frac{0.5}{2}}{7}=47 \% \text {. }
$$

To continue similarly with Equation 2 and 3 and by testing with Equation 4, we will get the result illustrated in figure 3.

Table 3 (p. 77) presents the inter-correlation matrix of 14 variables of the People, Process and Goal model. As mentioned in previous section, the correlation coefficients can vary numerically between o.o and 1.0. The closer the correlation is to 1.0, the stronger the relationship between the two variables. In this table 3, there are several correlation coefficients that indicate the existence of a medium to strong relationship, for example between the 'human relations' and 'coach' variables (0.91), or between the 'proactive' and 'future' variables (0.78). Conversely, the coefficient correlation between the 'planned career' and 'introvert' variables was very low (0.01) but this is logical and understandable because these two variables are independent of each other.

\section{Comparative Evaluation}

This study is motivated by following research questions:

- What are the major differences and similarities of the People, Process and Goal model and the Sand Cone model of transformational leadership?

- What are the major benefits and limitations of these models and how could the models be combined or prioritized? 


\section{What Are the Major Differences and Similarities of the People, Process and Goal Model and the Sand Cone Model of Transformational Leadership?}

The major similarities between the Sand Cone model and the People, Process and Goal model are that both are analytical and normative models. They are both aligned with organisational interests because the models can be taken as guidelines for leaders to follow and improve their leadership skills. Both models can be utilised as a compass for organisations when considering leadership-training programs. Finally, they can also be used for recruitment, selection or promotion purposes.

There are three main points indicate the connection between the Sand Cone model and the People, Process and Goal model. Firstly, the people-focused leadership behaviour has a direct relation to all elements included in the Sand Cone model, because four components of the Sand Cone (Resources, Results, Cornerstones and Direction of outputs) are always more or less focused on people. Secondly, the process-focused behaviour has a connection to three components of the Sand Cone model, (a) Resources component, because this component contains the process factor, (b) Results components and (c) Direction of outputs as different styles and performances involve processes. Thirdly, the goal-focused behaviour relates to the (a) Direction of outputs and (b) Results component of the Sand Cone model.

The differences between the Sand Cone model and the People, Process and Goal model are:

- The purpose of the Sand Cone model is to measure the effectiveness of transformational leadership behaviours, while the aim of the People, Process and Goal model is to measure the focus of leadership behaviours.

- The measurement of the Sand Cone model is reflecting the present situation, because the method using in the Sand Cone, the AHP-based questionnaire is measuring what leaders' behaviour and attitude is right now or in current situation. In contrast, the measurement of the People, Process and Goal model is reflecting future focus, because the aim was to investigate the leaders' behaviour in long terms aspects for example planned or unplanned career, human relations, proactive and so forth.

- The Sand Cone model uses Analytic Hierarchy Process-based survey, whereas the People, Process and Goal model is based on a survey, in-depth interviews and observations. 
table 4 Differences and Similarities between the Sand Cone and the People, Process and Goal Models

\begin{tabular}{lll}
\hline Differences & Similarities & Differences \\
\hline - To measure the & - Analytical \& normative & - To measure the focus of \\
effectiveness of TL & models & leadership behaviours \\
behaviours & - Aligned with & - Reflecting future facus \\
- Reflecting present & organisational interests & - Survey, interview, and \\
situation & - Enhance leadership & observation \\
- AHp-based survey & skills & - Measuring method: tri- \\
- Measuring method: & - Compass for leadership & angulation \\
mainly quantitative & training & - Three measure- \\
- Five measure- & - Recruitment tool & ments/equations \\
ments/equations & & - Has flexible target, acc. \\
- Has clear optimal & & to organisational types \\
target, clear indicators & & \\
\hline
\end{tabular}

- The measuring method for the Sand Cone model is mainly quantitative, while the measuring method of People, Process and Goal model is both qualitative and quantitative.

- Unlike the Sand Cone model, which uses five measurements or five formulas to calculate different indexes for leadership behaviours, the People, Process and Goal model uses three equations to calculate the leaders' focus areas reflecting their reallife experiences.

- Finally, the Sand Cone model has a clear optimal target, with index o being the worst, and index 1 being the best. The common traffic light colour in the Sand Cone model is a clear indicator for leaders to follow. In contrast, the People, Process and Goal model has flexible targets according to organisation types, (nonprofit versus profit organisation) such as the people-focused behaviour in a private company may not be the same as the peoplefocused behaviour in a public hospital and so forth.

Table 4 presents the differences and similarities between the Sand Cone and People, Process and Goal model.

\section{What are the Major Benefits and Limitations of These Models?}

By using these models, the leaders become more aware of their own competencies and opportunities. Subsequently, the leaders are able to improve their leadership skills and as a result, the skilful leaders have better prospect to retain their key followers. For the organisations, these models are practical, organisations not only can use them as a compass for leadership training programs but also as a recruitment tool for selection or promotion purposes. These models 
TABLE 5 Major Benefits and Limitations

\begin{tabular}{|c|c|c|}
\hline Model & Benefits & Limitations \\
\hline $\begin{array}{l}\text { Sand Cone } \\
\text { An analytical } \\
\text { model to mea- } \\
\text { sure the ef- } \\
\text { fectiveness of } \\
\text { transforma- } \\
\text { tional leaders. }\end{array}$ & $\begin{array}{l}\text { The model offers a guideline for leaders } \\
\text { to follow based on a profile with traffic } \\
\text { light colours and numeric indexes. } \\
\text { Can be used as a compass for leadership } \\
\text { development training programs. } \\
\text { Can be used for recruitment, selection or } \\
\text { promotion purposes. } \\
\text { Contributes to our understanding of how } \\
\text { internal and external factors impact on } \\
\text { leadership effectiveness (Ha-Vikström } \\
\text { and Takala 2016b). } \\
\text { A cost-effective of developing people to } \\
\text { ensure organisational success. }\end{array}$ & $\begin{array}{l}\text { Expertise is needed to } \\
\text { interpret the leader- } \\
\text { ship profile. } \\
\text { The structure of the } \\
\text { model seems to be } \\
\text { less rational due to the } \\
\text { ambiguous terminolo- } \\
\text { gies e.g. 'Results' and } \\
\text { 'Direction of outputs' } \\
\text { and might be less solid } \\
\text { because of weak cor- } \\
\text { relation between these } \\
\text { two components. }\end{array}$ \\
\hline $\begin{array}{l}\text { People, Process } \\
\text { and Goal } \\
\text { A normative } \\
\text { model to mea- } \\
\text { sure the key } \\
\text { focus areas of } \\
\text { leadership be- } \\
\text { haviour. }\end{array}$ & $\begin{array}{l}\text { The model offers diagnostic feedback of } \\
\text { leaders' key focus areas. } \\
\text { Can be used as a compass for leadership } \\
\text { development training programs. } \\
\text { Can be used for recruitment, selection or } \\
\text { to find the right competent leaders to the } \\
\text { right positions. } \\
\text { Contribute to our understanding of how } \\
\text { leadership behaviour manifests across } \\
\text { organisational levels. } \\
\text { A cost-effective of developing people to } \\
\text { sustain organisational success. } \\
\text { The model opens an avenue for further } \\
\text { research on leadership behaviour. }\end{array}$ & $\begin{array}{l}\text { This model is con- } \\
\text { structed based on a } \\
\text { single case study. } \\
\text { The attributes in the } \\
\text { model are blend of } \\
\text { different categories } \\
\text { (the attributes were } \\
\text { defined based on the } \\
\text { patterns in the inter- } \\
\text { views, survey and ob- } \\
\text { servations data). }\end{array}$ \\
\hline
\end{tabular}

can be cost-effective ways of developing people because the models will give a positive impact on employees' performance and productivity. In the same way, they will ensure employee satisfaction and motivation. Consequently, they will support succession planning for the company as well as ensure organisational success. Table 5 presents briefly the major benefits and limitations of the Sand Cone model and the People, Process and Goal model.

It is worth noting that the questionnaire is based on the Analytic Hierarchy Process principle, which increases the reliability and value of the Sand Cone model. Furthermore, the results from this measuring method in a large scale of participants (see Ha-Vikström and Takala 2016b; 2016c) may offer an important contribution to our understanding of how cultures, genders, education, working experience or financial status would influence the effectiveness of transformational leaders. These key factors can help organisa- 
tions to be proactive in developing their strengths and overcome the weaknesses, for example how to utilize the best resources or experiences/knowledge from senior leaders.

Alternatively, The People, Process and Goal model represents a unique aspect of leadership behaviour with specific consequences in three key focus areas for success in organisations: people, process and goal. This instrument and methodology for measuring the convergence of leadership behaviours will help businesses and organisations build consensus around common goals and ultimately achieve greater success.

\section{SELF-CRITIC EVALUATION}

The original Sand Cone model has its strength as many researchers have studied and developed it since 2005 (Takala et al. 2005; 2006; Takala, Kukkola, and Pennanen 2008; Kazmi and Takala 2012). Through a recent study by Ha-Vikström and Takala (2016a; 2016b; 2016c) to re-examine the model in a global business environment, some discrepancies were found in the transformational leadership index formulas. The model was improved with five new equations to provide accurate assessments to the leaders and a new comprehensive layout for the leadership profile. The improved Sand Cone model has now clear targets and clear indicators (to compare with the old one), which means all indexes are normalized by scaling between 0.00 and 1.00 (index 1.00 is the best and index 0.00 is the worst). In other words, the higher the index a leader obtains, the greater the essentiality of leadership effectiveness.

Despite several improvement have been done for the Sand Cone model, expertise are needed to interpret all details in a leadership profile in order to give 'a clear diagnostic comment to the leaders or coaching them to create a specific individual development plan' (Kang and Jin 2015). This is because two components (Results and Direction of outputs) in the Sand Cone model are to some extent ambiguous, as the terminology 'Results' can be interpreted similarly as 'Direction of outputs,' these two terms might not be a decisive description and may confuse the leader.

In addition, it may not be easy for a leader to understand the distinction between several elements in the model, for example between two elements 'people, technology, know-how' and 'organisation (groups, teams)' in the 'Resources' component, as to some extent both elements refer to people. Especially, the logical connection between the 'Cornerstones' component and 'Direction of output' as well as the defined optimal value for each element in the model 
seems to be inexplicit. Thus, these limitations might make the structure of the Sand Cone model less rational and solid.

Turning to the People, Process and Goal model, despite the fact that the three focus areas are apparent and easy to understand (people, process and goal), some guidelines and recommendations from the top or higher level of management teams about the healthiest balance for their own organisations are still needed. Admittedly, the biggest shortcoming of the People, Process and Goal model might be the attributes patterned in the model; one could ask why the attributes were a combination of different categories (coach versus results; facts versus philosophy, introvert versus extrovert and so forth). The answer is that the model describes the behaviour and attitude experienced by the leaders across different organisational levels. Those attributes were the findings based on in-depth interviews, survey, and observations in a global business organisation.

Furthermore, as mentioned in table 5, another limitation, which need to be acknowledged is that, the People, Process and Goal model was constructed based on a single case study (Ha-Vikström 2017). However, this limitation opens an avenue for further research. Our first recommendation is to conduct quantitative and/or qualitative research on this model in different organisational settings, for example for-profit organisations versus non-profit organisations, or the private sector versus the public sector in order to validate and verify the model. Secondly, as the People, Process and Goal model only measures the focus areas of leaders (regardless the leadership styles), the model does not concentrate on the healthiest balance for different types of organisations. Thus, further research to explore the relation between People, Process and Goal model and organisation performance would be needed.

A third suggestion for further research is to conduct more quantitative research on the Sand Cone model in multiple case studies in order to fine-tune the model. Finally, further research to explore the relation between the People, Process and Goal model and organisational transformational leadership performance is also recommended.

\section{HOW COULD THE MODELS BE COMBINED OR PRIORITISED?}

As can be expected, these two models extend the theories of leadership behaviours. The Sand Cone model is being used for short terms prospects, as it describes how the leaders behave at present. Conversely, the People, Process and Goal model is being used for long terms opportunities, it concentrates more on how the leaders trans- 
form his behaviour and attitude toward their followers. Based on these differences, each leader is recommended to utilise the Sand Cone model to enhance their leadership skills. While the higher level of management teams are recommended to use the People, Process and Goal model and to form or define the healthiest balance for their own organisation.

This implies that our studies on the two models have developed independently for partially different purposes. One model concentrates on the effectiveness of transformational leadership behaviour, while the other pays attention to the leaders' focus areas across different organisational levels regardless of the leadership styles. Therefore, this study suggests that every organisation should take the advantages of each model's strengths and apply on their own situation, as a golfer chooses his or her club, in order to maximize organisational effectiveness and success.

\section{Conclusion}

Poor leaders create dissatisfaction, conversely, great leaders make a great difference for organisational success (Culp and Smith 2005; Prinsloo 2012; Kang and Jin 2015) but without any helpful measurement tool, how can we define the great leaders and the poor leaders?

This study offers a critical evaluation of two practical tools that can help leaders to improve their leadership skills and to find their desired balance for their own organisation's target. These models and their assessing methods can be used for recruitment, selection or promotion purposes for any organisation. The major theoretical contribution of this study is the clarification of the values of two models and the justification of prioritizing one model over the other.

Overall, these two models offer a novel perspective on how leadership behaviour can be measured and analysed to scholars and practitioners. Top executives should take the benefits of each model's strengths and apply strategically on their own situation, in order to meet the challenges in today's turbulent and uncertain environment as well as to achieve and sustain organisational success.

\section{References}

Antonakis, J., and R. J. House. 2014. 'Instrumental Leadership: Measurement and Extension of Transformational-Transactional Leadership Theory.' The Leadership Quarterly 25:746-71.

Antonakis, J., D. V. Day, and B. Schyns. 2012. 'Leadership and Individual Differences: At the Cusp of a Renaissance.' Leadership Quarterly 23:643-50. 
Banks, G. C., K. D. McCauley, W. L. Gardner, and C. E. Guler, 2016. 'A Meta-Analytic Review of Authentic and Transformational Leadership: A Test for Redundancy.' The Leadership Quarterly 27 (4): 537712 .

Bass, B., and R. Riggio. 2006. Transformational Leadership. 2nd ed. Mahwah, NJ: Lawrence Erlbaum.

Bass, B., and P. Steidlmeier. 1999. 'Ethics, Character, and Authentic Transformational Leadership Behaviour.' The Leadership Quarterly 10 (2): 181-217.

Bono, J., and T. Judge. 2003. 'Self-Concordance at Work: Toward Understanding the Motivational Effects of Transformational Leaders.' Academy of Management Journal 46:554-71.

Brown, B. B. 2003. 'Employees' Organizational Commitment and Their Perception of Supervisors' Relations-Oriented and Task-Oriented Leadership Behaviors.' PhD Dissertation, Virginia Polytechnic Institute and State University, Blacksburg, vA.

Crossan, M. M., and M. Apaydin. 2010. 'A Multi-Dimensional Framework of Organizational Innovation: A Systematic Review of the Literature.' Journal of Management Studies 47 (6): 1154-91.

Culp, G., and A. Smith. 2005. 'Leadership Effectiveness and Behavior.' Leadership \& Management in Engineering 5 (2): 39-48.

Day, D. V., and R. G. Lord. 1988. 'Executive Leadership and Organizational Performance: Suggestions for a New Theory and Methodology.' Journal of Management 14:453-64.

Dirks, K., and D. Ferrin. 2002. 'Trust in Leadership: Meta-Analytic Findings and Implications for Research and Practice.' Journal of Applied Psychology 87 (4): 611-28.

Duffy, F. 2006. Power, Politics, and Ethics in School Districts: Dynamic Leadership for Systemic Change, Leading Systemic School Improvement. Lanham, MD: Rowman \& Littlefield.

Fischer, T., J. Dietz, and J. Antonakis. 2016. 'Leadership Process Model: A Review and Synthesis.' Journal of Management 43 (6): 1726-1753.

Flynn, F. J., and B. M. Staw. 2004. 'Lend Me Your Wallets: The Effects of Charismatic Leadership on External Support for an Organization.' Strategic Management Journal 25 (4): 309-30.

Gold, R. L. 1958. 'Roles in Sociological Field Observations.' Social Forces $36(3): 217-23$.

Ha-Vikström, T. 2017. 'People-, Process- and Goal-Focused Leadership Behaviour: An Empirical Study in a Global Company.' Management 12 (1): 75-103.

Ha-Vikström, T., and J. Takala. 2016a. 'Knowledge Management and Analytical Modelling for Transformational Leadership Profiles in a Multinational Company.' In Successes and Failures of Knowledge Management, edited by J. Liebowithz, 151-74. Cambridge: Elsevier.

- 2016b. 'Measuring Transformational Leadership Profiles: An 
Empirical Study across 21 Nations in a Multinational Company.' Theoretical Issues in Ergonomics Science 19 (1): 1-20.

- 2016c. 'Do Cultures, Genders, Education, Working Experience or Financial Status Influence the Effectiveness of Transformational Leaders?' Theoretical Issues in Ergonomics Science 19 (1): 21-41.

House, R. J., W. D. Spangler, and J. Woycke. 1991. 'Personality and Charisma in the us Presidency: A Psychological Theory of Leader Effectiveness.' Administrative Science Quarterly 36:364-96.

Jones, B. F., and B. A. Olken. 2005. 'Do Leaders Matter? National Leadership and Growth since World War ir.' https://economics.mit.edu/ files $/ 2915$

Judge, T. A., and R. F. Piccolo. 2004. 'Transformational and Transactional Leadership: A Meta-Analytic Test of Their Relative Validity.' Journal of Applied Psychology 89:755-68.

Jung, D., and B. Avolio. 1999. 'Effects of Leadership Style and Followers' Cultural Orientation on Performance in Group and Individual Task Conditions.' Academy of Management Journal 42:208-18.

Kang, S. K., and S. Jin. 2015. 'What Are the Best Practices to Assess Leadership Effectiveness?' http://digitalcommons.ilr.cornell.edu/ student/72

Kazmi, A., and Takala, J. 2012. 'Individual Differences in Work-Force Substantiate Greater Levels of Operational Responsiveness through Transformational Leadership.' Paper presented at the International Conference on Business Strategy and Organizational Behaviour, Singapore, 7-8 May.

Maclean, M., C. Harvey, and R. Chia. 2012. 'Sensemaking, Storytelling and the Legitimization of Elite Business Careers.' Human Relations 65 (1): 17-40.

McLeod, J. 2015. The History of India. 2nd ed. Santa Barbara, cA: ABcCLIO.

Mhatre, K. H., and R. E. Riggio. 2014. 'Charismatic and Transformational Leadership: Past, Present, and Future.' The Oxford Handbook of Leadership and Organizations, edited by David V. Day, 221-40. Oxford: Oxford University Press.

Prinsloo, M. 2012. 'Towards an Integrated Assessment of Leadership Potent.' Leadership Review 12 (1): 1-31.

Progen, M. D. 2013. 'Dynamic Leadership.' https://www.mcamarines.org /gazette/dynamic-leadership

Stephens-Craig, D., M. Kuofie, and R. Dool. 2015. 'Perception of Introverted Leaders by Mid to High-Level Leaders.' Journal of Marketing and Management 6 (1): 62-75.

Takala, J., H. Hirvela, P. Hiippala, and V. Nissinen. 2005. 'Management and Deep Leadership Sand Cone model for Human Resource Allocation, The First Phase of the Study.' Paper presented at the Fourth International Automation and Manufacturing Conference, 
ATDC (Advanced Technologies for Developing Countries), Slavonski Brod, 21-24 September.

Takala, J., H. Hirvela, P. Hiippala, and V. Nissinen. 2006a. 'Management and Deep Leadership Sand Cone Model for Human Resource Allocation, The Second Phase of the Study.' Paper presented at the Eleventh International Conference on Productivity and Quality Research, New Delhi, 12-15 December.

Takala, J., J. Leskinen, H. Sivusuo, J. Hirvelä, and T. Kekäle. 2006b. 'The Sand Cone Model: Illustrating Multi-Focused Strategies.' Management Decision 44 (3): 335-45.

Takala, J., J. Koskinen, Y, Liu, M. Serif Tas, and M. Muhos. 2013. 'Validating Knowledge and Technology Effects to Operative Sustainable Competitive Advantage.' Management and Production Engineering Review 4 (3): 45-54.

Takala, J., A. Kukkola, and J. Pennanen. 2008. 'Prospector, Analyzer and Defender Models in Directions of Outcome in Transformational Leadership.' Paper presented at the 17th International Conference on the Israel Society for Quality, Jerusalem, 18-20 November.

Takala, J., J. Pennanen, P. Hiippala, A. Maunuksela, and O. Kilpiö. 2008. 'Decision Maker's Outcome as a Function of Transformational Leadership.' In Simplify Leadership and Coaching Effectiveness, edited by T. Kinnunen, 67-86. Lahti: Deep Lead Oy.

Thoms, P. 2004. Driven by Time: Time Orientation and Leadership. Westport, ст: Praeger.

Waldman, D. A., and F. J. Yammarino. 1999. 'ceo Charismatic Leadership: Levels-of-Management and Levels-of-Analysis Effects.' Academy of Management Review 24:266-85.

Williams, L. E. 1998. Servants of the People: The 196os Legacy of AfricanAmerican Leadership. New York: St Martin's Press.

Yukl, G. 2008. Leadership in organizations. Upper-Saddle River, NJ: Pearson.

This paper is published under the terms of the Attribution-

NonCommercial-NoDerivatives 4.0 International (CC BY-NC-ND 4.0)

License (http://creativecommons.org/licenses/by-nc-nd/4.o/). 